\title{
Consumo de lácteos y enfermedad inflamatoria intestinal: ¿invertir la tendencia?
}

Taxonera C, Mendoza JL. Consumo de lácteos y enfermedad inflamatoria intestinal: ¿invertir la tendencia? An Med Interna (Madrid) 2004; 21: 209-211.

En la década de los 60 el grupo de Truelove describe una mejoría sintomática y una menor tendencia a la recidiva en pacientes con colitis ulcerosa (CU) que tomaban una dieta sin lácteos $(1,2)$. Estos estudios, que presentaban claros defectos metodológicos, extendieron la creencia de que la leche podría constituir un factor importante en la iniciación de la colitis ulcerosa o en su exacerbación una vez establecida. Lo cierto es que esa idea permanece vigente en la actualidad entre los pacientes con CU: en un estudio reciente los productos lácteos son el alimento que con mayor frecuencia evitan estos pacientes (3). En la enfermedad de Crohn la eliminación de lácteos en la dieta se ha basado no solo en la falta de tolerancia por malabsorción sino también en el hipotético y aún no demostrado papel que puede jugar en esta entidad la alergia a proteínas de la leche (4).

La lactosa requiere de la acción enzimática de la lactasa para dividirse en glucosa y galactosa. La lactosa no digerida que llega al colon es fermentada por las bacterias entéricas produciendo $\mathrm{H} 2$ y ácidos grasos de cadena corta que pueden causar dolor o distensión abdominal y en ocasiones diarrea. La deficiencia de lactasa intestinal depende de factores hereditarios que delimitan grupos étnicos con diferentes prevalencias (5). El déficit de lactasa suele dar lugar a malabsorción de lactosa, habitualmente determinada de manera indirecta mediante una prueba de $\mathrm{H} 2$ espirado positivo a la administración de cantidades variables de lactosa. Dado que el déficit de lactasa no suele ser completo, es mejor hablar de hipolactasia. Así una prueba de $\mathrm{H} 2$ espirado positiva con una dosis $\mathrm{x}$ de lactosa puede pasar a ser negativa con dosis inferiores de lactosa. La hipolactasia es un fenómeno que se desarrolla con el tiempo, por ello es más frecuente en los grupos de edad avanzada (6). No todos los sujetos con malabsorción de lactosa en la prueba de $\mathrm{H} 2$ espirado experimentan síntomas derivados del posterior metabolismo bacteriano de la lactosa no absorbida. El termino intolerancia a la lactosa se reserva para los pacientes que presentan estos síntomas al tomar lácteos.

La prevalencia de malabsorción de lactosa (determinada mediante test de $\mathrm{H} 2$ espirado) en pacientes con $\mathrm{CU}$ es similar $(7,8)$ o incluso inferior $(9,10)$ a la de los controles ajustados según grupos étnicos. Tampoco durante los brotes de CU se evidencia una tasa de malabsorción de lactosa superior a la del grupo control $(7,11)$.

En la enfermedad de Crohn (EC) los datos son algo más conflictivos. En pacientes con EC limitado a colon la tasa de malabsorción de lactosa con test de $\mathrm{H} 2$ espirado es atribuible al grupo étnico. En la EC de intestino delgado la prevalencia de malabsorción de lactosa supera la esperada para el grupo control $(9,12)$, siendo mas elevada cuando la enfermedad afecta a tramos proximales (duodeno o yeyuno) que cuando esta se limita a ileón (9). Sujetos sin déficit genético de lactasa pueden padecer deficiencias transitorias en relación con infecciones o inflamaciones agudas que reduzcan la expresión de las enzimas del borde en cepillo, y ello puede ocurrir en pacientes con EC con tramos proximales afectos (13). En pacientes con niveles normales de lactasa intestinal se pueden producir resultados falsos positivos en el test de $\mathrm{H} 2$ espirado en relación con sobrecrecimiento bacteriano o tránsito intestinal rápido.

Un estudio reciente despeja ciertos interrogantes al respecto (14). La prevalencia de intolerancia clínica a la lactosa es similar en controles y sujetos con EC sin actividad. En los pacientes con EC en brote (CDAI $>150)$ la tasa de intolerancia a lácteos $(46.9 \%)$ casi triplica la de los controles (16.6\%), y es independiente de la localización de la enfermedad (ileón, colon o ambos). En un 70\% de estos intolerantes a la leche el test de $\mathrm{H} 2$ espirado con lactosa es patológico. Sin embargo, ni la intolerancia a lácteos ni la malabsorción de lactosa en el test de $\mathrm{H} 2$ espirado se explican por un déficit de lactasa en mucosa duodenal: solo un $37.5 \%$ de los pacientes con EC en brote presentan niveles bajos de la enzima (frente a 33\% en el grupo control). En estos pacientes la determinación de lactasa en biopsia duodenal no es capaz de predecir la tolerancia a la leche: pacientes con hipolactasia no presentan síntomas y pacientes con lactasa normal refieren intolerancia y tienen un test de $\mathrm{H} 2$ espirado positivo. Los pacientes con EC en brote presentan con mas frecuencia déficit de lactasa duodenal, comparados con los enfermos sin actividad (14). Los pacientes con EC y resección intestinal tienen unas tasas de intolerancia a la leche y de malabsorción de lactosa similares a los no resecados (15). 
La hipolactasia del adulto se asocia a dos genotipos (C/C13910 y G/G-22018) localizados próximos al locus LCT, el gen que codifica la lactasa-phlorizin hidrolasa. La frecuencia de ambos genotipos en una población norteeuropea es igual de frecuente en pacientes con EC o CU y en familiares en primer grado de pacientes con EC, comparados con los individuos sanos (15).

En el artículo publicado en esta revista R. Baños y colaboradores estudian la incidencia de malabsorción de lactosa en pacientes con CU y EC sin actividad clínica (16). El estudio cuenta con un grupo control adecuado. Se investiga la malabsorción a lactosa mediante test de $\mathrm{H} 2$ espirado tras una carga media de lactosa (25g). La tasa de malabsorción de lactosa no muestra diferencias significativas entre los pacientes con enfermedad inflamatoria intestinal (16.6\%) y los controles (20\%), y se sitúa en el rango de la referida en nuestro medio para la misma carga de lactosa (17). En este estudio todos los pacientes con malabsorción de lactosa en el test de H2 espirado presentaban intolerancia a lactosa con síntomas floridos tras la ingesta de leche entera. Sin embargo, 25 (el 59.5\%) de los pacientes con enfermedad inflamatoria no tomaba productos lácteos, frente a solo 7 (16.6\%) que tenían malabsorcion de lactosa en el test de $\mathrm{H} 2$ espirado (16). Por tanto mas de un $40 \%$ de los pacientes no tomaban lácteos sin tener malabsorción de lactosa. En este estudio, al igual que sucede en otro realizado también en nuestro medio (11), la realización del test de $\mathrm{H} 2$ espirado puede ayudar a reintroducir los lácteos en un número significativo de pacientes con CU o EC.

Como conclusión podemos decir que tanto en la CU como en la EC sin actividad clínica los niveles de lactasa duodenal y la tasa de malabsorción de lactosa determinada mediante prueba de aliento son similares a los de la población sana. Los pacientes con EC en brote, y en especial si está afectado el intestino delgado, presentan una mayor incidencia de malabsorción de lactosa y de intolerancia a la leche. Este hecho no se explica totalmente por el déficit transitorio de lactasa en duodeno, y puede depender también de otros factores (sobrecrecimiento bacteriano, tránsito intestinal rápido). En la $\mathrm{CU}$ o en la EC la malabsorción de lactosa, de estar presente, no puede considerarse en ningún caso un factor para desencadenar un brote, y aún menos un factor causal de ambas entidades.

Por todo lo referido mas que pensar a que pacientes con CU o EC hay que suprimir la leche lo que hay que intentar es invertir la tendencia actual que hace que muchos pacientes $y$ no pocos médicos perciban los lácteos como algo perjudicial para estas entidades (3). Son mas los pacientes con enfermedad inflamatoria intestinal que no toman leche y que se pue- den beneficiar de su reintroducción que aquellos que pueden beneficiarse de su retirada. Es importante recordar que los pacientes con enfermedad inflamatoria intestinal y con intolerancia a la leche presentan una reducción en la densidad ósea de la espina lumbar (14). Aunque en la perdida de densidad ósea en la CU y EC intervienen otros factores (usos de corticoides, inflamación crónica, desnutrición) que parecen tener un mayor peso que el atribuible a una dieta pobre en calcio, no parece inteligente suprimir en estos pacientes su principal fuente: los lácteos (18).

Solo en pacientes con enfermedad inflamatoria en brote, en especial EC que afecta el intestino delgado, y que refieran síntomas (sobre todo diarrea) asociados a la toma de leche parece razonable suprimir esta, intentando mantener otros lácteos si son bien tolerados. En casos mas severos esta justificado suprimir totalmente los lácteos como parte de las dietas de eliminación o exclusión. Una vez pasado el brote lo razonable es tratar de reintroducir los lácteos. En pacientes con CU o EC sin actividad clínica la norma es la toma de lácteos como parte de la dieta. Si algún paciente no tolera la leche debe recomendarse que trate de sustituirla con otros lácteos. Si el paciente refiere no tolerar productos lácteos de ningún tipo parece razonable realizar un test de $\mathrm{H} 2$ espirado con cargas bajas de lactosa: $12.5 \mathrm{~g}$ o mejor aún su equivalente en leche entera $(250 \mathrm{cc})$. La prueba puede objetivar que el paciente realmente presenta malabsorción de lactosa o que sus síntomas dependen de otras causas. Hay que tener en cuenta que la llamada intolerancia a la leche con frecuencia no puede ser objetivada, y es mas una percepción del paciente: sujetos que consideran ser intolerantes a la lactosa presentan síntomas similares cuando beben leche normal o leche con lactosa hidrolizada (19). En nuestro medio la tasa de malabsorción de lactosa esperada tras la toma de un vaso de leche entera es baja (13.5\%) (17). En pacientes con prueba de aliento patológica y síntomas acompañantes parece razonable la retirada completa de lácteos y la sustitución de calcio a largo plazo, y la administración de sucedáneos de leches si así lo demandan.

No existe ninguna evidencia científica para prohibir sistemáticamente el consumo de productos lácteos en pacientes con CU o EC, y debemos además insistir en la importancia de estos productos como parte de la dieta de estos pacientes.

\section{TAXONERA, J. L. MENDOZA}

Unidad Enfermedad Inflamatoria Intestinal, Servicio Aparato Digestivo. Hospital Clínico San Carlos. Madrid

\section{Bibliografía}

1. Truelove SC. Ulcerative colitis provoked by milk. Br Med J 1961; 1 : 154-60.

2. Wright R, Truelove SC. A controlled therapeutic trial of various diets in ulcerative colitis. Br Med J 1965; 2: 138-41.

3. Jowett SL, Seal ChJ, Phillips E, et al. Dietary beliefs of people with ulcerative colitis and their effect on relapse and nutrient intake. Clin Nutr 2004; 23: 161-70.

4. Pearson M, Teahon K, Levi AJ. Food intolerance and Crohn's disease. Gut 1993; 34: 783-7.

5. Di Palma JA, Narváez RM. Prediction of lactose malabsorption in referral patients. Dig Dis Sci 1988; 33: 303-7.

6. Rao DR, Bello H, Warren AP, et al. Prevalence of lactose maldigestion. Influence and interaction of age, race and sex. Dig Dis Sci 1994; 39: 1519-24.

7. Bernstein ChN, Ament M, Artinian L, et al. Milk tolerance in adults with ulcerative colitis. Am J Gastroenterol 1994; 89: 872-7.

8. Ginard D, Riera J, Bonet L, et al. Malabsorción de lactosa en la colitis ulcerosa. Estudio de casos y controles. Gastroenterol Hepatol 2003; 26: 469-74.

9. Mishkin B, Yalovsky M, Mishkin S. Increased prevalence of lactose malabsorption in Crohn's disease patients at low risk for lactose malabsorption based on ethnic origin. Am J Gastroenterol 1997; 92: 1148-53. 
10. Hüppe $\mathrm{D}$, TrommmA, Langhorst $\mathrm{H}$, et al. Lactose intolerance in chronic IBD. Dtsch Med Wochenschr 1992; 117: 1550-5.

11. Rosinach M, Maurer-Pons A, Doménech, E et al. ¿Es necesario suprimir los lácteos de la dieta en los brotes de la enfermedad inflamatoria intestinal? Gastroenterol Hepatol 2002; 24: 198-9.

12. Pironi I, Callegari C, Cornia GL, et al. Lactose malabsorption in adult patients with Crohn's disease. Am J Gastroenterol 1988; 83: 1267-71.

13. Dunne WT, Cooke WT, Russel RI. Enzimatic and morphometric evidence for Crohn's disease as a diffuse lesion of the gastrointestinal tract. Gut 1977; 18: 290-4.

14. von Tirpitz C, Kohn C, Steikamp M, et al. Lactose intolerance in active Crohn's disease. Clinical value of duodenal lactase analysis. J Clin Gastroenterol 2002; 34: 49-53.

15. Buning C, Ockenga J, Kruger S, et al. Genotypes for adult-type hiplo- lactasia are not associated with inflammatory bowel disease. Scan J Gastroenterol 2003; 38: 538-42.

16. Baños R, Salama H, Morán S, Gallardo F, Albaladejo A, Mercader J. Malabsorción de lactosa en pacientes con enfermedad inflamatoria intestinal inactiva: ¿está justificado excluir de la dieta la leche a todos los pacientes? An Med Interna (Madrid) 2004; 21: 212-214.

17. Leis R, Tojo R, Pavón P, et al. Prevalence of lactose malabsorption in Galicia. J Pediatr Gastroenterol Nutr 1997; 25: 296-300.

18. Silvennoinen J, Lamberg-Allardt C, Kärkkäinen M, et al. Dietary calcium intake and its relation to bone mineral density in patients with inflammatory bowel disease. J Intern Med 1996; 240: 285-92.

19. Suárez FL, Dennis AsS, Levitt MD. A comparison of symptoms after the consumption of milk or lactose-hodrolized milk by people with selfreported severe lactose intolerance. N Engl J Med 1995; 333: 1-4. 